\title{
Article
}

\section{Low level light therapy in the management of paediatric oral and oropharyngeal mucositis}

McDowall, F, O'Murchu, N and Welbury, Richard Available at http://clok.uclan.ac.uk/18686/

MCDowall, F, O'Murchu, N and Welbury, Richard ORCID: 0000-0002-9322-2440 (2017) Low level light therapy in the management of paediatric oral and oropharyngeal mucositis. Dental Update, 44 (6). pp. 541-548. ISSN 0305-5000

It is advisable to refer to the publisher's version if you intend to cite from the work.

For more information about UCLan's research in this area go to http://www.uclan.ac.uk/researchgroups/ and search for < name of research Group>.

For information about Research generally at UCLan please go to http://www.uclan.ac.uk/research/

All outputs in CLoK are protected by Intellectual Property Rights law, including Copyright law. Copyright, IPR and Moral Rights for the works on this site are retained by the individual authors and/or other copyright owners. Terms and conditions for use of this material are defined in the policies page.

\section{CLoK}

Central Lancashire online Knowledge www.clok.uclan.ac.uk

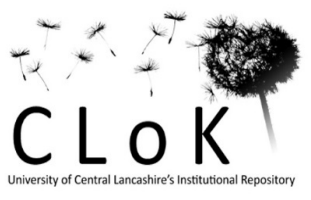




\section{Paediatric Dentistry}

\section{Low level light therapy in the management of paediatric oral and oropharyngeal mucositis}

Fiona McDowall: BDS, MFDS, Specialist Registrar in Paediatric Dentistry, Leeds Dental Institute/ North Yorkshire Community Dental Services

fiona.mcdowall@nhs.net

Nora O'Murchu: BDS, MFDS, MPaedDent, Specialist Registrar in Paediatric Dentistry, Glasgow Dental Hospital/ Royal Hospital for Children, Glasgow no'murchu@nhs.net

Richard Welbury: MB BS, BDS, PhD, FDSRCS, FDSRCPS, FRCPCH, Hon FFGDP. Professor of Paediatric Dentistry, University of Central Lancashire rwelbury@uclan.ac.uk 


\section{Abstract (100 words)}

Oral and oropharyngeal mucositis is a common, debilitating condition experienced by patients undergoing oncology treatment. There are many different management strategies, with low level light therapy (LLLT) an emerging field.

Ongoing research on the topic of LLLT for mucositis has resulted in LLLT being included in national clinical guidelines. The number of centres currently using LLLT for paediatric patients with oropharyngeal mucositis is growing, with Glasgow having successfully used this treatment method for a number of years.

Across medicine and dentistry, LLLT is coming to the fore and is a treatment modality we should all be aware of.

\section{CPD/Clinical Relevance}

New technologies and treatment modalities are areas that practitioners should stay up to date with. Low level light therapy continues to be a growing research field.

Objective: The reader should understand the significance of oral and oropharyngeal mucositis for the paediatric oncology patient and the relevance of low level light therapy towards its management. 


\section{Oral and Oropharyngeal mucositis}

Oral and oropharyngeal mucositis occurs in $52-80 \%$ of children undergoing treatment for cancer. ${ }^{1}$ Mucositis is a debilitating condition which can be so severe it can delay or stop oncology treatment. The mucositis disease process is initiated by chemotherapy or radiotherapy at 0-2 days, followed by cell damage at 2-10 days. Frank ulceration and mucosal damage occurs at 10-15 days and finally healing after 2-3 weeks. The clinical presentation is a combination of erythema and ulceration; and as healing begins, mucosal sloughing affects the intra-oral tissues and oesophageal tract. Maintaining adequate oral hygiene is difficult due to oral discomfort which may further exacerbate the condition and increase a patient's vulnerability to developing infection. The consequences for paediatric patients are significant; eating, drinking, speaking and engaging with those around them can be significantly restricted which presents concerns regarding recovery and physical and mental wellbeing. Psychological distress has been described by parents of children suffering from mucositis at a time when stress and anxiety of the parent and child is already amplified by many other factors. ${ }^{2}$

Figure 1

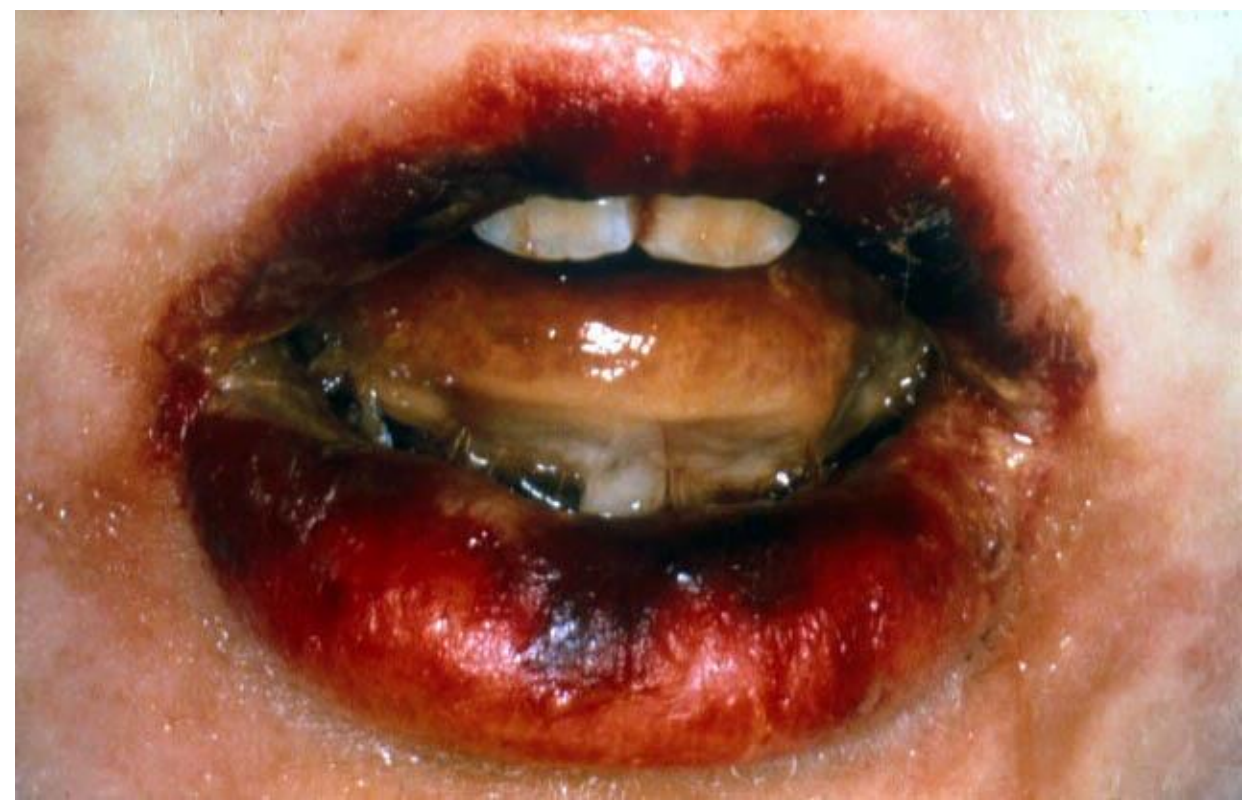


Mucositis can be graded using the 'World Health Organisation (WHO) Grading,' which comprises gradings zero to four ${ }^{3}$, as can be seen in the table below. Both the clinical presentation and functional outcomes form the basis for this grading system:

\begin{tabular}{|c|l|}
\hline \multicolumn{2}{|c|}{ WHO Mucositis Grading } \\
\hline WHO Grading & Description \\
\hline 0 & Pealthy mucosa \\
\hline 1 & $\begin{array}{l}\text { Ulcers and erythema but the patient is still able to } \\
\text { swallow a solid diet }\end{array}$ \\
\hline 2 & \begin{tabular}{l} 
The patient cannot swallow a solid diet; \\
\hline 3
\end{tabular} \\
\hline 4 & $\begin{array}{l}\text { Mucositis is so severe that alimentation is not } \\
\text { possible }\end{array}$ \\
\hline
\end{tabular}

\section{Management of mucositis}

General management of mucositis often involves a mixture of preventive and symptomatic control measures such as; oral hygiene instruction, soft diet, cryotherapy, protective gels, analgesics ranging from paracetamol and non-steroidal analgesia to narcotic analgesia, topical anaesthetics, benzydamine hydrochloride sprays or mouthwashes and chlorhexidine and calcium phosphate mouthrinses. Many of these, for example mouthwashes, require a certain degree of cooperation and maturity which not all paediatric patients will have. Mucositis is such a common and significant problem in oncology that many different guidelines have been developed to assist practitioners. Guidelines published in 2012 by the The Royal College of Surgeons of England and The 
British Society for Disability and Oral Health ${ }^{4}$ recommend benzydamine hydrochloride mouthwash, cryotherapy, intravenous keratinocyte growth factor-1 (palifermin), anaesthetic mouthwash and analgesia as options to consider in the management of mucositis. More recent guidelines published in 2014 by the Multinational Association of Supportive Care in Cancer/International Society of Oral Oncology (MASCC/ISOO) similarly advises most of the above mentioned interventions along with other weaker evidence for options such as doxepin mouthwash and zinc supplements. ${ }^{5}$ A guideline by Sung et al in 2015 included a weak recommendation for cryotherapy to prevent mucositis. ${ }^{6}$ Both MASCC/ISCOO ${ }^{5}$ and Sung et al ${ }^{6}$ also recommend LLLT as an option for managing mucositis. It is anticipated with new evidence emerging that all future guideline revisions will also soon advocate Low Level Light Therapy.

\section{Low Level Light therapy}

Low level light therapy (LLLT) is emerging as an effective treatment modality in both medicine and dentistry for a range of conditions. LLLT involves the use of a low power laser emitting less than $500 \mathrm{~mW}$ on the red or near infra-red spectrum with light wavelengths of $600 \mathrm{~nm}-1000 \mathrm{~nm}$. On applying the light to areas of the body, cells are stimulated thereby reducing inflammation, increasing cell metabolism and inducing endorphins. A Dental Update article by Milward et al. in $2014{ }^{7}$ describes in further detail the mechanism of action including wound repair, analgesia and anti-inflammatory effects. The combination of cellular effects has led to this therapy becoming a widely studied topic and gathering increasing attention from the medical and dental professions. Despite the growing body of evidence, a recent systematic review of by Hadis et al ${ }^{8}$ found inadequacies in the reporting of LLLT studies, with incomplete information available on wavelength, light source type, power, pulse frequency, beam area, irradiance, exposure time, radiant energy and fluence 
As mentioned, low level light therapy can be considered for a number of different conditions. Research in medical patients has resulted in a Cochrane review on the use of LLLT in rheumatoid arthritis, providing evidence that it reduces pain and stiffness. ${ }^{9}$ Systematic reviews on its use in treating trigeminal neuralgia ${ }^{10}$ and recurrent aphthous ulceration ${ }^{11}$ are also available in the literature. Ayyildiz et al discusses LLLT for use on patients suffering from Temporomandibular Joint Dysfunction with limited mouth opening. ${ }^{12}$ There has also been research involving orthodontic patients concerning the potential for LLLT to accelerate tooth movement and also reduce orthodontic related pain 13,14

\section{Low Level Light therapy and mucositis}

In the literature there have been many studies involving LLLT as a treatment modality for oral and oro-pharyngeal mucositis. In a systematic review with meta-analysis by Bjordal et al, ${ }^{15}$ Low Level Light Therapy was shown to reduce pain, severity and duration of mucositis. This paper included 11 randomised placebo controlled trials with a total of 415 patients. The relative risk of developing mucositis was found to be significantly reduced after LLLT when compared to placebo $(R R=2.03 p$ value $=0.02)$. In patients with mucositis, the number of days patients had mucositis was found to be reduced for severity gradings 2 or more from 4.38 days to 1.33 days compared with placebo.

A randomised controlled study by Khun et al $^{16}$ in 2009 , recommended LLLT as a first-line option in paediatric patients with chemotherapy-induced oropharyngeal mucositis. The trial compared treatment for mucositis with placebo for 5 days compared to LLLT for the same duration of time. Twenty-one patients were included in the study with the number of days 
patients had mucositis decreasing from a mean duration of 8.9 days with placebo to a mean duration of 5.8 days with LLLT.

The benefits that LLLT can offer to the paediatric patient appear to be significant. As this is often a patient group where cooperation may be limited, quick, efficient and effective treatment is necessary. In addition paediatric oncology patients in particular are a group where the prevention of infection and pain are of paramount importance.

\section{Low Level Light therapy use for paediatric patient in Glasgow}

Currently in the Royal Hospital for Children (previously The Royal Hospital for Sick Children) in Glasgow, LLLT is used daily in the management of oro-pharyngeal mucositis by the Paediatric Dentistry department. It is used often in conjunction with previously described measures such as mouth rinses, analgesia and protective gels. The paediatric dental team makes regular visits to the oncology ward and has a good relationship with the ward staff allowing a team approach to the provision of LLLT. LLLT is delivered using a Diobeam 830 laser $(830 \mathrm{~nm}$ ) with an output of $150 \mathrm{~mW}$ (see Figure 2). Bensadoun at al $2015^{17}$ recommended that wavelengths of $633-685 \mathrm{~nm}$ or $780-830 \mathrm{~nm}$ and power output between 10 and $150 \mathrm{~mW}$ are used to treat mucositis.

Figure 2 
Initially an extra- and intra-oral examination by a qualified dentist determines the areas affected by mucositis and a WHO mucositis grading is assigned. An administered dose $(\mathrm{J} / \mathrm{cm} 2)$ is then delivered according to the severity of mucositis. ${ }^{3}$ The paperwork completed for each treatment episode used can be seen below in Figure 3. Although in Glasgow the' laser' is primarily used for symptomatic mucositis, one joule setting per centimetre squared is available for use on healthy mucosa, which would allow for the laser to be given as prophylactic treatment. The Diobeam laser is classed as a 3B laser which means it carries an ocular hazard. Local laser safety precautions are employed, such as using safety glasses to protect the patient, parent's and user's eyes. The laser is used in an approved room which has blinds on the windows, a locked door and safety signs displayed outside. LLLT is not visible but has a red guide light to help the user to visualise the target area and an auditory guide for when the laser is active. Treatment is painless. Similar to radiographic regulations, there are also local laser rules which have to be followed and training must be completed prior to any clinician delivering treatment.

Figure 3

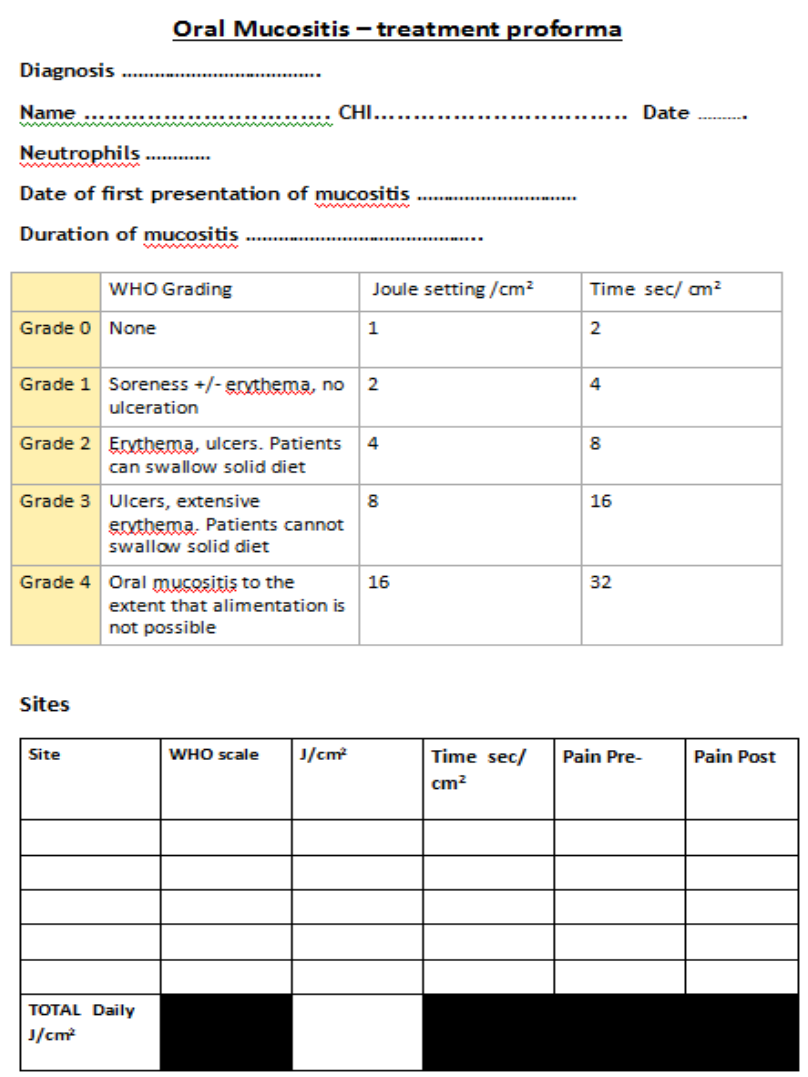


A pilot study completed in 2012 involving 15 patients demonstrated a statistically significant reduction in self-reported pain levels for children who had treatment with LLLT for mucositis. A larger, retrospective case note analysis was then undertaken, comprising 319 separate LLLT sessions in 39 patients undergoing LLLT treatment from January 2013 to July 2014. Paediatric patients with symptomatic oro-pharyngeal mucositis were included (aged 4-17 years old). Patients were excluded from this analysis if they were not able to communicate their pain score due to communication ability or age. The Diobeam 830 laser was used for all treatment, with administered dose $(\mathrm{J} / \mathrm{cm} 2)$ varying according to the severity of mucositis (WHO scale $1-4)$. The pain scores (0-10) were recorded prior to and immediately post-treatment on a visual/faces analogue scale (Figure 4), along with daily neutrophil counts. Neutrophils are the most common white blood cell and in this group of patients the counts vary greatly depending upon their stage of disease and type of treatment.

Figure 4

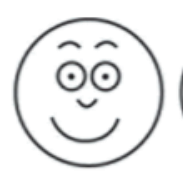

0 No Hurt 2 Hurts
Little Bit

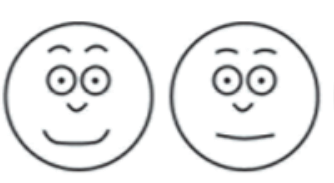

4 Hurts
Little More

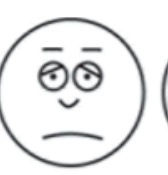

6

Hurts Even More
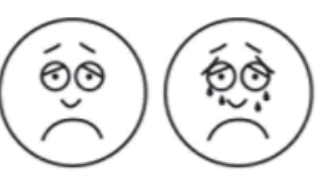

10

Hurts

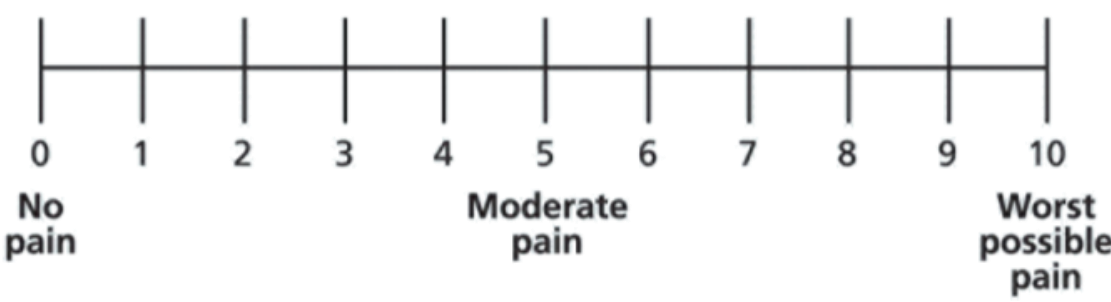

Over 9 years old 
The results are summarised in the Tables $1-4$ below. The most common WHO grade for mucositis was Grade 3 (extensive erythema and ulceration and cannot swallow a solid diet). A statistically significant change in pain score was noted with the median change of pain score being 2 (P-value $<0.0005)$. No statistically significant relationship between neutrophil count and pain response was found $(P$-value $=0.263$ ), or indeed between pain response and type of tumour (blood/solid) $(P$-value $=0.121)$.

\section{Results}

Sumn

\section{WHO Grading}

0

1

2

3

4
Number of patients

8

38

79

149

45

WHO Gradings pre-LLLT of the 319 episodes of treatment analysed

\section{Type of Tumour}

Solid tumour

Blood borne

Inherited blood disorders

Solid and blood borne

\section{Number of Patients}

19

14

5

1

Table 1: Summary of malignancies and WHO Gradings 


\section{Analysis of Pain Scores}

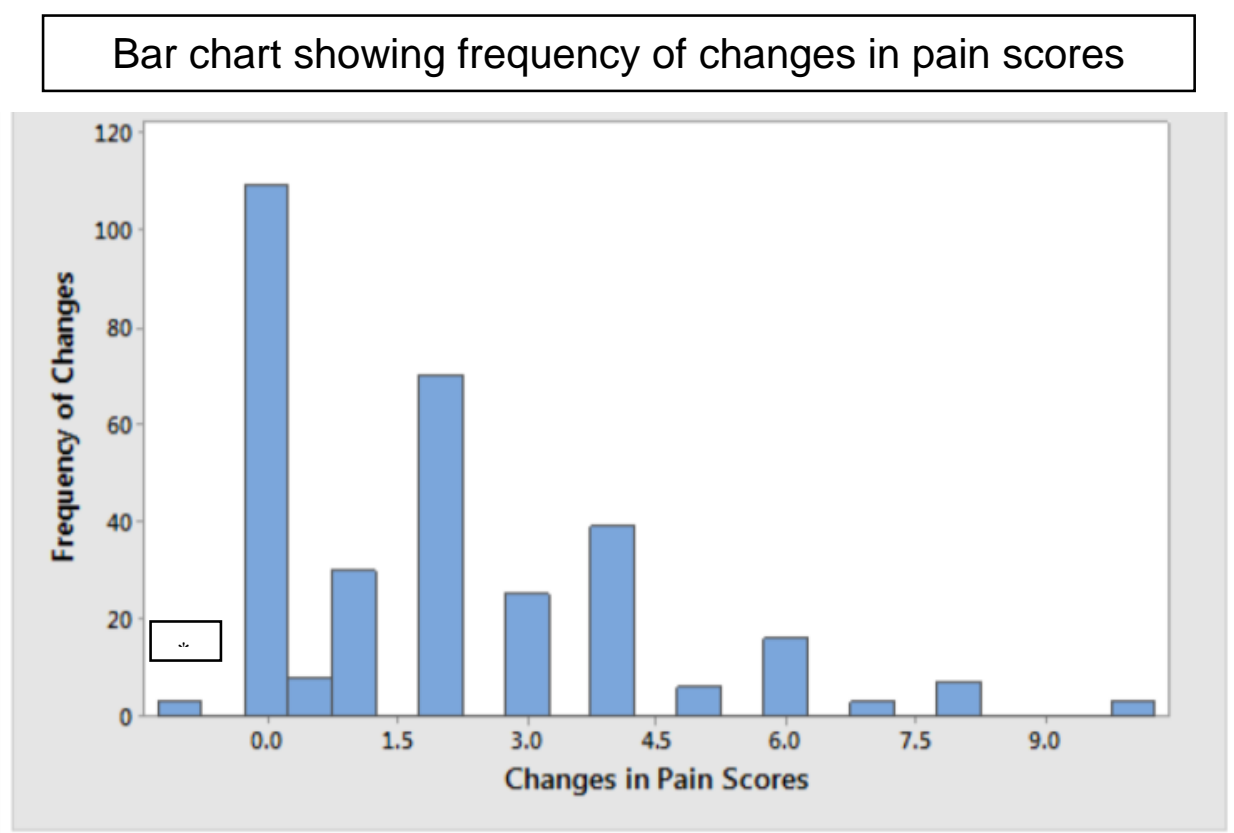

patient reported an increase in pain score

Median change of pain score: 2 units

P-value $<0.0005$

For example: $8 / 10$ pain score pre-treatment to $6 / 10$ post-treatment

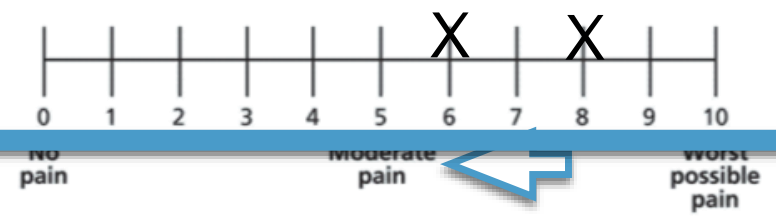

Table 2: Pain change results and number of patients with these changes 


\section{Neutrophil count of patients at the time of LLLT}

\section{Bar chart showing frequency of neutrophil counts}
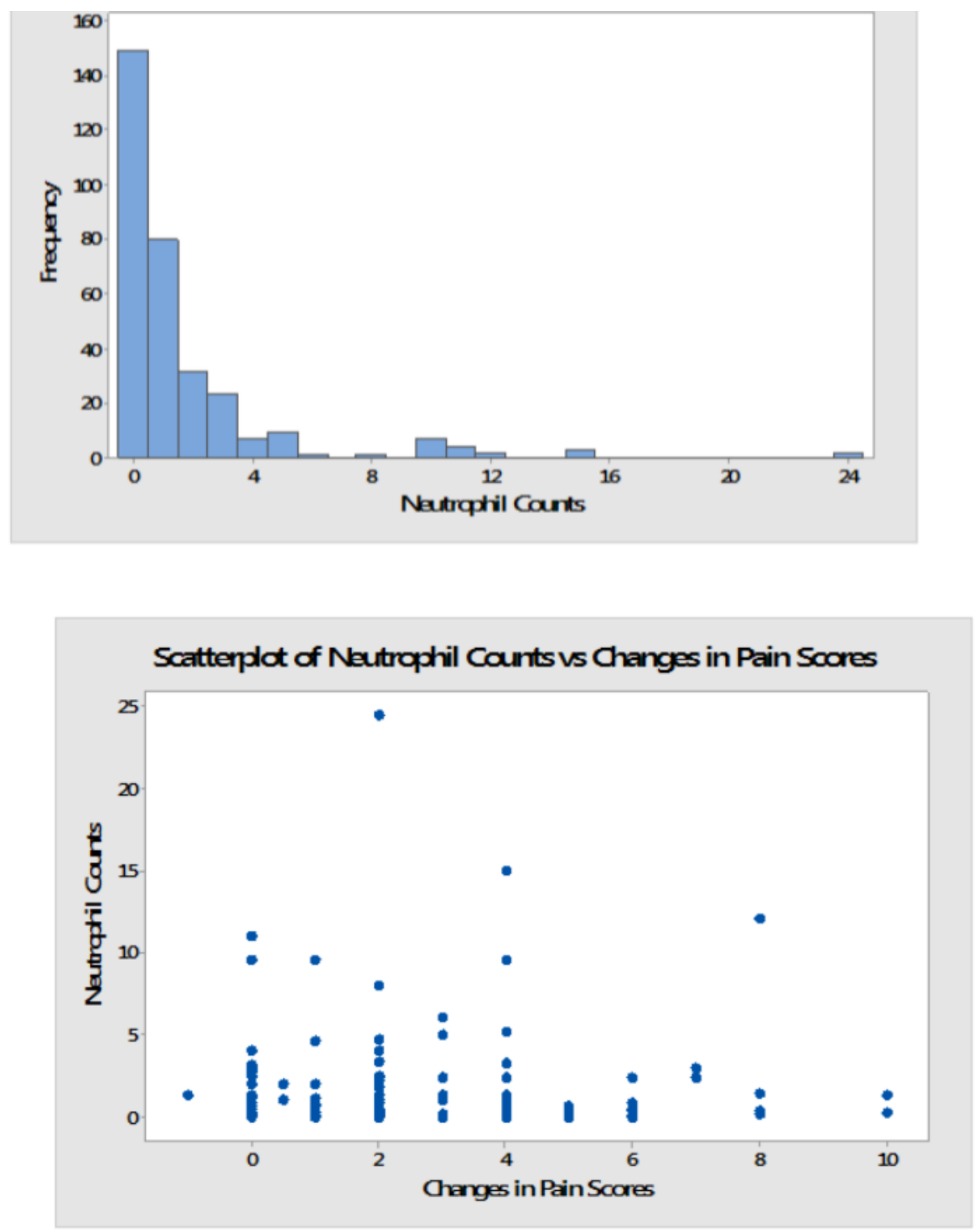

No statistical relationship between neutrophil count and pain response was found $(P$-value $=0.263$ ) 
Table 3: Summary of neutrophil counts at the time of LLLT treatment and comparison with changes in pain scores.

\section{Pain Response versus Type of tumour}

No statistical relationship between pain response and type of tumour, whether blood borne or solid tumour. $(P$-value $=0.121)$

$\underline{\text { Table 4: Pain change and tumour results }}$

Parents, staff and patients have embraced LLLT, finding it easy and beneficial, with regular requests for treatment and many positive reports. The ward and dental team work closely to ensure LLLT is available to those patients who need it and it has been widely accepted by the medical team as an effective management tool for mucositis.

Currently in Glasgow, due to resources and staff availability, LLLT is mainly provided when patients develop symptomatic mucositis. Our research has shown the ability to reduce pain in this patient group and this theoretically should reduce the need for narcotic analgesia and allow patients to maintain oral diets. This has been supported with one of the pain nurses in Glasgow stating that, 'The laser provides better pain relief than ketamine.' A patient explained when asked about LLLT 'my mouth was a 10/10, now it's a 0/10.' Figueiredo et al in $2013{ }^{18}$ conducted a meta-analysis of the prophylactic use of LLLT to prevent mucositis and showed a significant positive effect. This research may extend our provision of LLLT, utilizing the lowest setting on the laser to provide this. 


\section{Conclusion}

As with all new technologies, availability and cost naturally become less of a consideration over time. Access to LLLT across medical and dental services will no doubt improve, alongside cost effectiveness. A study by Bezinelli et al (2014) has already demonstrated that oncology patients with mucositis not treated with LLLT had 30\% higher hospitalisation costs, ${ }^{19}$ an important finding for NHS hospitals under mounting financial pressures. Provision of LLLT is straightforward, quick and effective for many conditions. LLLT use within the specialist dental services continues to expand throughout the UK transforming the care we are able to routinely provide. Its use is also expanding in other areas of dental health and it will be interesting to see what the future holds for this remarkable technology.

\section{Acknowledgements}

Jennifer Kirby, Jonathan Love and Andy Hunter for their involvement in the studies carried out in Glasgow. 


\section{References}

1. Cheng K. K. F., Chang A. M., Yuen M. P. Prevention of oral mucositis in paediatric patients treated with chemotherapy; a randomised crossover trial comparing two protocols of oral care. European Journal of Cancer 2004;40,1208-1216.

2. Cheng, K. K. F. Oral mucositis: a phenomenological study of pedriatic patients' and their parents' perspectives and experiences. Supportive Care in Cancer 2009; 17, 829-837.

3. World Health Organization. Handbook for reporting results of cancer treatment. World Health Organization, Geneva, Switzerland, 1979: 15-22.

4. N.Kumar N, Brooke A, Burke M, John R, O'Donnell A, Soldini F. The Oral Management of Oncology Patients Requiring Radiotherapy, Chemotherapy and/or Bone Marrow Transplantation. The Royal College of Surgeons of England in association with the British Society for Disability and Oral Health. 2012 Update.

5. Lalla RV, Bowen J, Barasch A et al. MASCC/ISOO clinical practice guidelines for the management of mucositis secondary to cancer therapy. Cancer 2014;120(10):1453-1461.

6. Sung L, Robinson P, Triester $\mathrm{N}$ et al. Guideline for the prevention of oral and oropharyngeal mucositis in children receiving treatment for cancer or undergoing haematopoietic stem cell transplantation. BMJ Support Palliate CRE 2015;0:1-10.

7. Milward R, Holder M, Palin W, Hadis M, Carroll J, and Cooper R. Low Level Light Therapy (LLLT) for the Treatment and Management of Dental and Oral Diseases. Dent Update 2014; 41: 763-772.

8. Hadis MA, Zainal SA, Holder MJ, Carroll JD, Cooper PR, Milward MR, Palin WM. Lasers in Medical Science. Lasers Med sci 2016 May; 4:789809. 
9. Brosseau L, Welch V, Wells A G, De Bie, Gam, Harman K, Morin M, Shea B, Tugwell. Low level laser therapy (Classes I, II and III) for treating rheumatoid arthritis. Cochrane Library 2005.

10. Falaki F, Nejat AH, Dalirsani Z. The Effect of Low-level Laser Therapy on Trigeminal Neuralgia: A Review of Literature. Dent Res Dent Clin Dent Prospects. 2014 Winter; 8(1):1-5.

11. Vale FA, Moreira MS, de Almeida FC, Ramalho KM. Low-level laser therapy in the treatment of recurrent aphthous ulcers: a systematic review. Scientific WorldJournal 2015; Epub 2015 Mar 23.

12. Ayyildiz S, Emir F, Sahin C. Evaluation of Low-Level Laser Therapy in TMD Patients. Case Rep Dent. 2015;2015:424213. Epub 2015 Oct 26.

13. Long H, Zhou Y, Xue J, Liao L, Ye N, Jian F, Wang Y, Lai W. The effectiveness of low-level laser therapy in accelerating orthodontic tooth movement: a meta-analysis. Lasers Med Sci. 2015 Apr;30(3):1161-70.

14. Nóbrega C, da Silva EM, de Macedo CR. Low-level laser therapy for treatment of pain associated with orthodontic elastomeric separator placement: a placebo-controlled randomized double-blind clinical trial. Photomed Laser Surg. 2013 Jan; 31(1):10-6.

15. Bjordal JM, Bensadoun RJ, Tunèr J, Frigo L, Gjerde K, Lopes-Martins RA. A systematic review with meta-analysis of the effect of low-level laser therapy (LLLT) in cancer therapy-induced oral mucositis. Support Care Cancer 2011; 19: 1069-1077.

16. Kuhn A, Porto FA, Miraglia P, Brunetto AL.J . Low-level infrared laser therapy in chemotherapy-induced oral mucositis: a randomized placebocontrolled trial in children. Pediatr Hematol Oncol. 2009 Jan;31(1):33-7.

17. Bensadoun R, Nair R. Low-Level Laser Therapy in the Management of Mucositis and Dermatitis Induced by Cancer Therapy. Photomedicine and Laser Surgery Volume 33, Number 10, 2015.

18. Figueiredo $A L$, Lins L, Cattony AC, Falcão AF. Laser therapy in the control of oral mucositis: a meta-analysis. Rev Assoc Med Bras. 2013 Sep-Oct;59(5):467-74. Epub 2013 Oct 10. 
19. Bezinelli LM1, de Paula Eduardo F, da Graça Lopes RM, Biazevic MG, de Paula Eduardo C, Correa L, Hamerschlak N, Michel-Crosato E. Costeffectiveness of the introduction of specialized oral care with laser therapy in hematopoietic stem cell transplantation. Hematol Oncol. 2014 Mar;32(1):31-9. Epub 2013 Apr 29.

\section{Figures}

- Figure 1: Severe grade 4 oral mucositis

- Figure 2: Diobeam 830 Laser used in Glasgow

- Figure 3: The LLLT treatment sheet used in Glasgow

- Figure 4: Pain scales used in Glasgow

\section{Tables 2 and 3}

Graphs taken from statistical report by Johnathan Love B.Sc. 'Investigating the low level light therapy in paediatric patients suffering from chemotherapy induced oropharyngeal mucositis.' 